Canadian Journal of Fisheries and Aquatic Sciences Journal canadien des sciences halieutiques et aquatiques

\title{
Dusky sharks (Carcharhinus obscurus) undertake large- scale migrations between tropical and temperate ecosystems
}

\begin{tabular}{|r|l|}
\hline Journal: & Canadian Journal of Fisheries and Aquatic Sciences \\
\hline Manuscript ID & cjfas-2017-0313.R1 \\
\hline Manuscript Type: & Article \\
\hline Date Submitted by the Author: & $20-$ Nov-2017 \\
\hline $\begin{aligned} \text { Complete List of Authors: } \\
\text { Is the invited manuscript for } \\
\text { consideration in a Special } \\
\text { Issue? : }\end{aligned}$ & $\begin{array}{l}\text { Braccini, Matias; WA Fisheries and Marine Research Laboratories, } \\
\text { Le Lestang, Simon; Western Australian Fisheries and Marine Research } \\
\text { McAuley, Rory; WA Fisheries, }\end{array}$ \\
\hline Keyword: & $\begin{array}{l}\text { SHARKS < Organisms, MIGRATION < General, ACOUSTIC EQUIPMENT < } \\
\text { General, CONSERVATION < General, COMMERCIAL FISHERIES < General }\end{array}$ \\
\hline & \multicolumn{2}{|c}{} \\
\hline
\end{tabular}

\section{SCHOLARONE




\section{Dusky sharks (Carcharhinus obscurus) undertake large-scale}

\section{2 migrations between tropical and temperate ecosystems}

$3 \quad$ Matias Braccini ${ }^{1}$, Simon de Lestang and Rory McAuley

$4 \quad$ Western Australian Fisheries and Marine Research Laboratories, Department of Fisheries of

$5 \quad$ Western Australia, PO Box 20, North Beach, WA 6920, Australia

$6 \quad{ }^{1}$ Correspondence author. E-mail: Matias.Braccini@fish.wa.gov.au

7 Running title: Quantifying dusky shark migration

8 Abstract: Understanding the large-scale migrations of marine predators can allow better

9 representation of their population dynamics. The migration biology of dusky sharks

10 (Carcharhinus obscurus), a cosmopolitan large marine predator with very low resilience to

11 fishing, was quantified using a large-scale network of acoustic receivers deployed across

12 Western Australia. Time-series plotting of individual shark detections and modified logistic

13 modelling were used to determine the timing of acoustically-tagged sharks' seasonal

14 migration, the proportion of the population migrating and the size at which sharks start to

15 migrate. Large ( $>200 \mathrm{~cm}$ fork length) dusky sharks migrated between areas closed (north)

16 and open (south) to commercial shark fishing. There was limited evidence that smaller sharks

17 occurred in the northern study area, whereas several larger individuals of both sexes

18 undertook repeated north-south displacements, moving between disparate ecosystems within

19 the Indian Ocean $\left(21.7-35.4^{\circ} \mathrm{S}\right)$ and covering round-trip distances of 2,000-3,000 km per

20 migratory event. For migrating individuals, the probability of occurring in the north was high

21 in the austral winter/spring and low (males) to moderate (females) during the austral

22 summer/autumn. 
24 Key-words: ontogenetic shift, acoustic tagging, reproduction, migration

25

26 


\section{Introduction}

28 The regular movement of individuals is an increasingly observed phenomenon in nature

29 where migratory individuals can move between widely separated and ecologically different

30 locations (Webster et al. 2002). In the context of fisheries assessment, disregard of fish

31 movements can lead to erroneous conclusions and inappropriate or ineffective management

32 decisions (Guan et al. 2013). Hence, understanding the features of fish movement can allow

33 better representation of their population dynamics and may help to avoid negative outcomes

34 such as over-exploitation, unnecessary regulation or economic loss (Hilborn 1990; Lorenzen

35 et al. 2010).

36 Many shark species for which movement dynamics have been studied (e.g. white,

37 Carcharodon carcharias, blue, Prionace glauca, whale, Rhincodon typus, basking,

38 Cetorhinus maximus, sharks) move frequently and over considerable ranges, with many

39 species undertaking large-scale movements (100s to $1000 \mathrm{~s}$ of $\mathrm{km}$ ), including coastal,

40 transoceanic and trans-equatorial migrations (Chapman et al. 2015; Braccini et al. 2016).

41 Seasonal movements from breeding to non-breeding sites have been observed for some shark

42 species (e.g. Hueter et al. 2005). However, movement information has rarely been

43 incorporated in the modelling of sharks' population dynamics (Braccini et al. 2016), which

44 may be a significant caveat to accurate assessment when sharks are exposed to differing

45 levels of fishing mortality along their migratory paths. Taking explicit account of movement

46 can improve the precision of population estimates; for example, uncertainty in southern

47 Australian school shark (Galeorhinus galeus) population estimates decreased from 15-45\%

48 to $12-18 \%$ when movement among regions was incorporated to the modelling process

49 (Walker et al. 2008). 

$2009)$, although they are less common in north-eastern $\left(>123^{\circ} \mathrm{E}\right)$ and south-eastern $\left(118^{\circ} \mathrm{E}\right)$ waters (Simpfendorfer et al. 1999; McAuley et al. 2005). The population occurring off WA is known to be genetically-distinct from that off eastern Australia (Geraghty et al. 2014); however, the extent of any functional and genetic exchange with Indonesian or other regional populations is currently unknown. Off WA, dusky sharks are distinctly size-segregated, with neonates and younger juveniles occurring in nearshore waters off the south-west and adult sharks most-commonly found in waters off the north and north-western coasts (McAuley et al. 2005; Braccini \& Taylor 2016). A commercial gillnet fishery targeting neonate and young juvenile dusky sharks has operated off the south-west of WA since the 1970s and, until 2001/02, this species was the dominant component of the fishery's catch, with peak landings of 586 tonnes in 1988/89 (McAuley, 2010). Commercial shark fishing in the north-west of WA (North of $26^{\circ} 30^{\prime} \mathrm{S}$ and West of $114^{\circ} 06^{\prime}$ E) was prohibited in 1993 to provide protection for the dusky shark breeding stock.

Following a $60 \%$ reduction in the value of Individual Transferrable Effort (ITE) units, primarily to reduce catches of another target species, whiskery shark (Furgaleus macki), stock assessments indicated that fishing mortality rates experienced by dusky shark cohorts born in 1994/95 and 1995/96 were sustainable (Simpfendorfer et al. 1999; McAuley et al. 2007). However these assessments also indicated that the sustainability of those catches was dependent on negligible mortality of older sharks. Subsequent catch rate analyses, however, indicated that recruitment continued to decline through the 1990s and early 2000s, most probably as a result of cryptic fishing mortality of older juvenile and adult sharks (McAuley et al. 2007). Additional measures were therefore introduced to mitigate any cryptic mortality of older dusky sharks, which include prohibitions on the use of commercial shark fishing gear throughout north-western waters and retention of shark catches in almost all non-target 
75 fisheries, as well as the introduction of a maximum size limit for the species in the target

76 fisheries and a spatial closure to protect the breeding stock (McAuley et al. 2005; Heupel \&

77 McAuley 2007). However, the extent to which older sharks remain vulnerable to capture during southerly movements into areas where they are exposed to elevated risks of capture cannot be accurately determined due to a lack of information about those movements. This study therefore aims to quantify the timing of migration, rates of movement, the proportion of the population migrating and the size at which dusky sharks start to migrate.

Materials and methods

\section{Data collection}

85 The large-scale movement patterns of dusky sharks were studied using a network of acoustic

86 receivers deployed across WA consisting of three large arrays (Ningaloo, Perth and Southern

87 arrays) (Fig. 1). Detection data were collected from Vemco VR2W acoustic receiver stations

88 generally deployed as gates (with receivers deployed $\sim 800 \mathrm{~m}$ apart) by the Department of

89 Fisheries (DoF) and the Integrated Marine Observing System's Animal Tracking Facility.

90 The DoF also deployed and maintained a gate off Perth on behalf of the Ocean Tracking

91 Network (OTN, see Table S1 for a summary of receiver numbers per array and refer to

92 McAuley et al. 2016 for a detailed description of receiver mooring and rigging). Acoustic

93 receivers were downloaded approximately once per year between 2012 and 2016. Shallow

94 water receivers $(<30 \mathrm{~m})$ were retrieved by scuba divers, whereas deep water receivers $(>30 \mathrm{~m})$

95 were retrieved by a combination of acoustic release mechanisms and a Remotely Operated

96 Vehicle (McAuley et al. 2016). 
Tagging involved implanting uniquely-coded acoustic transmitters (Vemco V16-5x$69 \mathrm{KHz}$, transmission intervals of 100-200 seconds and estimated tag life of 10 years) into the body cavity of sharks via a small incision on the ventral surface using standard surgical procedures (e.g. Heupel et al. 2004). Sharks were also fitted with an external conventional yellow plastic Jumbo Rototags (Dalton Supplies, Australia) on the first dorsal fin to allow their visual identification and the reporting of capture details. Sharks were tagged (Table S2) during fishery-independent longline research cruises in northern WA between 2011 and 2015 ( $\mathrm{n}=91$ sharks), in southern WA between 2012 and 2013 ( $\mathrm{n}=11)$ and during commercial gillnet fishing operations in the south-west in 2013 (n=2) (Fig. 1). This range covered most of the spatial distribution of this species in Western Australia, and since a wide size range of both sexes was tagged across multiple years, the tagged population was assumed to represent the greater population as a whole. Longlines were $\sim 500 \mathrm{~m}$ long and comprised of $\sim 50$ 12/0 Jshaped hooks baited with sea mullet (Mugil cephalus) or mackerel (Scombridae) and attached to the main line via $\sim 2 \mathrm{~m}$ metal snoods. Longlines were set demersally in depths of $7-450 \mathrm{~m}$ (with 90\% set in < $192 \mathrm{~m}$ deep). Longlines were generally set between 04:00 and 07:00 during research cruises in the north and between 05:00 and 18:00 in the south, with soaktimes typically ranging between 2.5 and 6 hours (median of 3.5 hours). Tagged sharks were measured to the nearest $\mathrm{cm}$ (fork length, FL) and sexed. Dates and GPS coordinates were also recorded.

\section{Data analyses}

Overall analyses and data manipulations were conducted in the statistical package $\mathrm{R}$ (R Development CoreTeam 2014). Residency time lines and maps were used for graphical representation of the temporal and spatial movement patterns. To aid visualization and analysis of migratory patterns, detections by receivers in the Ningaloo array (3 lines and 
121 clusters) were grouped as 'northern detections' and detections from the Perth and Southern

122 arrays (4 lines) were grouped as 'southern detections'.

Distance travelled was quantified as the minimum linear displacement (in km)

124

125

126

127

128 between the locations of receivers with consecutive detections. To minimise movement trajectories crossing over land, three arbitrary co-ordinates (off North West Cape, Shark Bay and Cape Leeuwin, Fig. 1) were used as turning points. Round-trip migratory events were defined as a shark being detected by arrays in the north then south then north or south then north then south.

Based on the detection of the same sharks in both the northern and southern arrays throughout the study period, which shows migration behavior, and the fact that all small sharks were only detected in the southern area, we have assumed that the proportion of all sharks detected within the northern array represents the proportion of the tagged population which had migrated north from the southern area. Thus the proportion migrating north was quantified for each sex separately using a modified logistic model fitted in JAGS (Plummer 2003), using the equation;

$$
P_{l, s, m}=\alpha_{s, m} / 1+e^{\left(l-\beta_{s}\right) \varphi_{s}}+\tau_{t}
$$

where $P_{l, s, m}$ is the proportion of detected sharks of length $l$ and sex $s$ occurring in the north in month $m ; \alpha_{s, m}$ is the upper asymptote of the model and thus the maximum proportion of detected sharks for that sex-month; $\beta_{s}$ is the estimated length at which $50 \%$ of $\alpha_{s, m}$ sharks migrate; $\varphi_{s}$ is the rate of change between the length of sharks from not migrating to migrating; and $\tau_{t}$ is a random effect of shark $t$, used to account for multiple observations being derived from the same individuals. Model code is supplied in the Supplementary 
143 Material section (S3). $\beta_{s}$ and $\varphi_{s}$ varied between sexes but not between months since we

144 considered it unlikely that the size at which sharks migrated would change markedly between

145 months. This assumption was based on a visual assessment of Figs 3 and 4 and the relatively

146 slow growth rates of larger dusky sharks (Simpfendorfer et al. 2002), i.e. it was assumed that

147 a shark that migrated in one month will still be of a similar size six-twelve months later. Also

148 due to the unbalanced design given the nature of acoustic monitoring, observations from

149 different years were grouped so the effect of inter-annual variation in movement was not

150 considered in the model. Data were pooled to one record per individual per month. If an

151 individual was detected in the north in a month it was assigned a response value of 1 , whereas

152 if all detections for that shark in that month were recorded south, it was assigned a response

153 value of 0 . Of the 581 monthly shark detections (after grouping each shark by month and

154 year) three had detections in both the north and south within the same month. In all three

155 cases, the shark was detected within the first six days of a month in the north and then

156 detected within the last eight days of the month in the south (identifying a southern migration

157 in these months). For these three observations the response value assigned was both a 1 and a

158 0, i.e. each observation was repeated twice, one observation in the north and one in the south.

159 Detections also included the original tagging event, i.e. if a shark was tagged in the north it

160 was considered to be in the north in that month and assigned a response variable of 1.

161 Unknown parameters were estimated using Markov Chain Monte Carlo simulations

162 (MCMC). The model was run twice, with and without the random effects parameters, each

163 with $2,000,000$ iterations, three chains, a thinning rate of 50 and a burn-in of 10,000 . The

164 models achieved good visual mixing between chains for each parameter (based on the

165 examination of trace, histogram and empirical cumulative distribution function plots) and the

166 Gelman-Rubin statistics ( $R$; Gelman \& Rubin 1992), which were $\leq 1.0004$ for each parameter,

167 well below the commonly used cut off of 1.2. Combined, this information indicated good 
168 model convergence for both models. The deviance information criterion (DIC) was calculated 169 for each model to assess the benefits of the incorporation of random effects into the model. If 170 random effects were found to provide an improvement to the model they were retained in the 171 model framework, otherwise they were omitted and the model outputs were reported from the 172 simpler (non-random effects) model.

\section{Results}

175

176

177

Between 2011 and 2015, we acoustically tagged 104 dusky sharks (66 females, 37 males, and one individual of undetermined sex), ranging from 136 to $297 \mathrm{~cm}$ fork length (FL) (Table S2). Sixty four sharks (44 females, 23 males, one individual of undetermined sex) were detected across the monitored area (Fig. 1) between August 2011 and December 2016, generating $>15,000$ detections. The remaining 40 tagged sharks have not been detected as of December 2016. The detected sharks ranged 150-297 cm FL. Based on the species' mean size at 50\% maturity (254 and $191 \mathrm{~cm}$ FL for females and males, respectively, McAuley et al. 2007), these individuals were sub-adults and adults. Median detection period (i.e. the period between the first and last detection) was 601 days ( \pm 526 days, SD) with a maximum of 1632 days.

Dusky sharks showed extensive spatial use throughout WA (Fig. 1). Fifty one individuals were detected by the Ningaloo array, mostly by receivers located between 50 and $100 \mathrm{~m}$ deep. For the Perth array, 30 individuals were detected, particularly at the outermost receivers (150-198 m deep) and no individual was detected by the inshore receivers. For the Southern array, 43 individuals were detected across the extent of the three receiver lines but mostly by receivers located between 50 and $100 \mathrm{~m}$ deep. 
Thirty individuals were detected moving between northern and southern arrays and 23

192

193

194

195 individuals (15 females and eight males) completed round-trip migrations (i.e. were detected in one location, then in another and then back in the original location; Figs 2-4). Most of these individuals (11 females and four males) completed one round-trip migration. The remainder completed 1.5 (one female and one male), 2.5 (one female and one male), 3 (one male) and 4 (two females, one male) round-trip migrations. Sharks completing one round-trip migration covered distances of 2,000-3,000 km in 180-1,100 days whereas those completing $1.5,2.5,3$ and 4 round-trip migrations covered distances of 3,500-4,500, 5,600-6,300, 7,500 and 9,000-10,100 km in 600-1,200, 800-1200, 1,450 and $\sim 1,400$ days, respectively (Fig. 2). Most of the north-south and south-north displacements were done at between 5 and 10 $\mathrm{km}_{\text {day }}{ }^{-1}$; however, some of the displacements were considerably faster (Fig. 2c).

Female (Fig. 3) and male (Fig. 4) dusky sharks showed complex movement patterns and did not reside within any detection array for very long (Table 1). Most of the larger individuals showed regular displacements between the northern and southern arrays and a seasonal pattern in spatial distribution where most individuals were detected in the south during the austral summer/autumn (Fig. 5).

Comparison of the two movement models (with and without random effects) based on their DIC indicated that the two models were equally appropriate (DIC 350.6 and 351.5 with and without random effects, respectively). As such the more parsimonious model (without random effects) was chosen and all model outputs (Table 2) have been based on this. Movement patterns were strongly related to shark size. Smaller individuals of both sexes were only detected in the south whereas larger individuals showed north-south and south-north displacements (Figs 3 and 4 ). The mean (and $\pm 95 \%$ credible intervals, CI) size at which $50 \%$ of females and males start to migrate was similar $(222$ and $212 \mathrm{~cm} \mathrm{FL,}$ respectively) (Table 2; Fig. 6). 
The probability of a shark occurring in the north varied with month and sex (Table 2).

217 There was a higher probability of being detected in the north during winter/spring than during summer/autumn (Fig. 6). For the winter/spring period, the probability of a shark occurring in the north was $>0.9$ for females and up to 0.94 for males, whereas for the summer/autumn period, this probability was $\sim 0.5$ for females and as low as 0.12 for males. For males, model estimates had higher uncertainty (e.g. the lower limit of the $95 \%$ CI was close to zero between January and April, Fig. 6) because there was little contrast in the presence/absence of sharks in the north due to the limited number of detections in this location during summer/autumn (Fig. 4).

\section{Discussion}

Dusky sharks showed extensive spatial use throughout WA. This pattern is consistent with the habitat use of large dusky sharks, which are capable of deep dives (573 m) but prefer continental shelf and shelf edge waters shallower than $100 \mathrm{~m}$ (Rogers et al. 2013) to $125 \mathrm{~m}$ (Hoffmayer et al. 2014) deep. In addition, the scale of movement observed in our study is comparable to the migratory displacements of dusky sharks in South Africa (Hussey et al. 2009) and of other coastal sharks of similar size, such as bull sharks (C. leucas) (Daly et al. 2014) and grey nurse sharks (Carcharias taurus) (Dicken et al. 2007; Bansemer \& Bennett 2011). In eastern Australia, a large proportion of the bull shark population undertakes roundtrip migrations of up to $1,400 \mathrm{~km}$ (Espinoza et al. 2016) whereas mature female grey nurse sharks undertake biennial reproductive migrations at a scale of a few thousand km along the eastern coasts of South Africa (Dicken et al. 2007) and Australia (Bansemer \& Bennett 2011). 
$240 \quad$ Female and male dusky sharks showed complex movement patterns with larger

241 individuals showing regular displacements between the northern and the southern arrays and

242 a seasonal pattern in spatial distribution. Environmental, biological and ecological drivers

243 (e.g. temperature, wind speed, reproduction, prey availability) have been proposed to explain

244 seasonal patterns of shark occurrence (e.g. Schlaff et al. 2014; Lea et al. 2015; Espinoza et al.

245 2016). Changes in sea temperature may trigger the movement of dusky sharks out of Spencer

246 Gulf, South Australia (Rogers et al. 2013). Sea temperature is indirectly linked to the

247 large/scale movements of dusky sharks in South Africa, where dusky sharks (primarily

248 juveniles) undertake feeding migrations to capitalize on squid spawning aggregations and

249 sardine migrations, which are indirectly affected by temperature (Hussey et al. 2009). In our

250 study, the peak in number of shark detections in the north occurred approximately during the

251 shortest days of the year which coincides with a period of cool, decreasing water

252 temperatures. Day length patterns have been correlated with the behavior of other shark

253 species. For example, juvenile sandbar (C. plumbeus) (Grubbs et al. 2005) and grey nurse

254 (Kneebone et al. 2012) sharks emigrate from estuaries as day length (both species) and

255 temperature (grey nurse sharks) decrease. Whether dusky shark migration is associated

256 directly or indirectly with environmental drivers warrants further research; additional

257 information on factors affected by day length and temperature (e.g. prey availability) is

258 needed to avoid spurious correlations.

259 Smaller dusky sharks were only detected in the south whereas larger individuals

260 showed north-south and south-north displacements. The observed size at migration is similar

261 to the species' size at maturity (McAuley et al. 2005; Romine et al. 2009). In addition, dusky

262 sharks show strong size-segregation patterns in WA, where large individuals occur mostly in

263 the north-west but the nursery grounds occur in the south-west of WA (McAuley \&

264 Simpfendorfer 2003; Braccini \& Taylor 2016). In the western North Atlantic, large dusky 
sharks can migrate from the Gulf of Mexico (GoM) up the east coast of the US, where known nursey areas are located, but neonates are rarely observed in the GoM (Hoffmayer et al. 2014). Ontogenetic differences in migratory and range-expansion patterns have been reported for other large coastal shark species (Speed et al. 2010). For example, only large juvenile and adult bull sharks undertake long-range movements off the East coast of Australia (Heupel et al. 2015) and small/immature tiger sharks overwinter around Bermuda with only large individuals undertaking repeated long-distance migrations across the western North Atlantic (Lea et al. 2015).

Only a proportion of large female dusky sharks undertook annual southwards migrations, which would suggest a partial migration (sensu Chapman et al. 2012) where females do not reproduce every year and only term females migrate to parturition sites (in the south in our study). This behavior has been reported for tiger sharks (Papastamatiou et al. 2013). The reproductive cycle of female dusky sharks is $>1$ year, possibly up to three years (McAuley et al. 2005; Romine et al. 2009). Hence, only a portion of the female population gives birth on any given year. During the austral summer/autumn, about $50 \%$ of the detected female population was detected in the south so the probability of occurring north was not zero, which would be expected for a species with an annual cycle. Three females, however, migrated from the north to the south and back again four times ( 2 individuals of $230 \mathrm{~cm}$ FL) and 2.5 times ( 1 individual of $210 \mathrm{~cm} \mathrm{FL)} \mathrm{in} \mathrm{consecutive} \mathrm{years.} \mathrm{These} \mathrm{individuals} \mathrm{were}$ below the size at $50 \%$ maturity $(254 \mathrm{~cm} \mathrm{FL}$, McAuley et al. 2007) so it is possible that they have just started to develop migration behavior without actually being pregnant.

In WA, females give birth in the south-west of the state, between February and June (Simpfendorfer et al. 1999), which coincides with the time period when large females were mostly detected in the south. Finally, both adult males and females undertake the seasonal migration. Hence, the observed size and timing of migration, and the proportion of the 
detected population involved in the migration indicate that dusky sharks undertake repeated long-scale migrations for at least giving birth. Mating opportunities are a migration driver for tiger sharks (Lea et al. 2015). For dusky sharks, the time and location of mating is unknown and, as both sexes occur north and south during similar time periods, it is unclear if the observed migration is also done for mating purposes.

Our study supports the link between body size, dispersal ability and migration propensity, where larger individuals can disperse further and undertake regular migrations (Chapman et al. 2012). This behavior is selected for when an individual can maximize its fitness by capitalizing on resource distributions, such as food availability and juvenile survival, that are dominated by seasonality rather than by local patchiness (Shaw \& Couzin 2013). Large dusky sharks moved between tropical and subtropical ecosystems (north), characterized by coral reefs and tropical species (most of them endemic to this region), and temperate ecosystems (south), characterized by temperate rocky reefs, seagrass and kelp habitats (Fletcher \& Santoro 2012). By repeatedly moving from tropical to temperate areas dusky sharks show considerable ecological adaptability. This pattern is more commonly observed in oceanic sharks (e.g. Skomal et al. 2009; Jorgensen et al. 2010) but a few recent studies show that other large coastal sharks, such as tiger and bull sharks, are capable of a high degree of plasticity in ecosystem use (Heupel et al. 2015; Lea et al. 2015; Espinoza et al. 2016).

Given the scale of our study and the inherent restrictions of acoustic telemetry, our findings have several limitations. It was logistically impractical to monitor the detection range of each receiver within each receiver array throughout the study period so it is possible that detection abilities might have differed among receivers and/or arrays. In addition, $238 \%$ of the tagged individuals were not detected. This could be due to a combination of receiver detection failure, non-detected sharks exhibiting different behaviors (e.g. very high residency 
to release sites away from the detection range) or swimming deeper than our deepest receivers (198 m deep), tagging mortality, and/or non-detected sharks being captured by fishers but not reported.

\section{Management implications}

The full extent of dusky sharks' movements could not be determined within the geographic limits of the acoustic receiver arrays. Significantly though, the study area spanned the full extent of the target gillnet fishery and the area closed to shark fishing in the northwest of the State (McAuley 2010). Thus, the results from this study are directly applicable to defining the risks of migrating sharks being taken as bycatch in the target fishery for juveniles, which demographic assessments have repeatedly demonstrated need to be minimised (Simpfendorfer et al. 1999; McAuley et al. 2007). Detection patterns show that larger sharks are most likely to occur south of the protected area during summer and autumn, which corresponds to the peak in parturition in south-western WA (Simpfendorfer et al. 1999). Due to a combination of target species' availability and favourable weather conditions, demersal gillnet fishing effort also traditionally peaks during autumn and again in spring when larger dusky sharks are most likely to be north of the demersal gillnet fishing grounds. These results suggest that the concurrence of adult dusky sharks' movements into the southern half of WA and peak in demersal gillnet fishing effort leads to the highest bycatch risk occurring in Autumn.

Unfortunately though, the distribution of receiver arrays, which was designed for studies of other species (McAuley et al. 2016; Babcock et al. 2017) did not allow for evaluation of dusky sharks' movements in the north of their range. Although this species is known to be distributed across northern Australia (Last \& Stevens 2009) and occurs more than $1200 \mathrm{~km}$ to the north-east of the study area, the objectives of the projects that deployed 
339 receivers did not require monitoring off the north coast of WA. Also, the width of the

340 continental shelf off northern WA, exposure to cyclones and other practical constraints means

341 that monitoring dusky shark movement through the northern part of their range would be

342 extremely challenging. The lack of acoustic monitoring infrastructure north of the Ningaloo

343 array would also help to explain why $\sim 38 \%$ of tagged sharks were not detected during this

344 project. A targeted demersal longline fishery for sharks that took and retained dusky sharks,

345 operated off the north coast of WA prior to 2006 until concerns about its impacts on sandbar

346 sharks led to significant restrictions on its operation and fishing activity ceased. There has

347 since been continued interest in a resumption of shark fishing in the WA North Coast Shark

348 Fishery and if fishing should resume, obtaining a better understanding of dusky shark

349 movements across the north coast would help in developing new management arrangements

350 that did not compromise the sustainability of continuing catches in the southern half of WA.

351 Similarly, the lack of receivers between the Ningaloo and Perth arrays limited our

352 ability to detect tagged sharks' movements that did not extend as far south as the Perth array

$353\left(\sim 32^{\circ} \mathrm{S}\right)$. As neonate dusky sharks are regularly caught more than $400 \mathrm{~km}$ to the north of this

354 array, the location of receiver infrastructure may not have been sufficient to capture the full

355 extent of the species' southerly migrations, if these are linked to parturition. In these cases,

356 sharks passing through the Ningaloo array, may either not be detected by the Perth or more

357 southerly arrays at all or be influenced by different pre- and post-parturition motivations to

358 migrate. Regardless of the unquantified frequency of migrations that did not extend between

359 receiver arrays, additional information would be required to fully account for migrating

360 sharks' exposure to bycatch risks between Perth and the area in which they are protected off

361 the north-west.

\section{Conclusions}


The reported large-scale movements of dusky sharks highlight the importance of spatial management for highly mobile shark species. In this study, we showed that most of the monitored large dusky sharks undertake seasonal migrations between areas closed and open to commercial shark fishing [N.B. recreational fishers do not typically target sharks in the northern closure (Ryan et al. 2015)]. We determined the timing of migration, the proportion of the population migrating and the size at which sharks start to migrate. Although dusky sharks have been sustainably-managed in Western Australia for many years (Braccini \& O'Malley 2017), our findings could provide additional safeguards for the species' conservation and management. Current assessments are based on monitoring catch and effort trends from highly size-selective (predominantly neonates and young juveniles) shark gillnet fisheries. Our study, however, shows that adult sharks spend a considerable proportion of their time outside the area closed to shark fishing, being exposed to currently unquantified levels of fishing mortality. Better understanding the incidental catch levels of large dusky sharks is therefore required. Future assessments could make explicit use of the movement information generated in this study by developing spatial models that take into account the migratory behaviour of dusky sharks to make spatial and temporal predictions of age-specific fishing mortality. This will directly inform management on whether catch levels are sustainable. More generally, we showed how acoustic telemetry can be used to quantify migratory movements for marine species.

\section{Acknowledgements}

We thank professional fishers Jeffrey and Daniel Cooke and James Tindall for allowing research staff on their boat to undertake shark tagging, Ian Keay, Silas Mountford and several other staff for tagging sharks and servicing acoustic receivers, and Brent Wise, Dan Gaughan, 
387

388

389

390

391

392

393

394

Lindsay Joll and three anonymous reviewers for their comments on an earlier version of the manuscript. We also thank the Ocean Tracking Network project and the Integrated Marine Observing System's Animal Tracking Facility for their considerable investment in acoustic receiver infrastructure off the Western Australian coast. This work was supported by an Australian Fisheries Research and Development Corporation grant (FRDC 2010/003).

\section{References}

Babcock, R.C., Pillans, R.D., and Rochester, W.A. 2017. Environmental and individual effects on the behaviour and spawning movements of Lethrinus nebulosus on a coral reef. Marine and Freshwater Research 68:1422-1437.

Bansemer, C.S., and Bennett, M.B. 2011. Sex- and maturity-based differences in movement and migration patterns of grey nurse shark, Carcharias taurus, along the eastern coast of Australia. Marine and Freshwater Research 62:596-606.

Braccini, M., Aires-da-Silva, A., and Taylor, I. 2016. Incorporating movement in the modelling of shark and ray population dynamics: approaches and management implications. Reviews in Fish Biology and Fisheries 26:13-24.

Braccini, M., and Taylor, S. 2016. The spatial segregation patterns of sharks from Western Australia. Royal Society Open Science 3:160306.

Braccini, M., and O'Malley, J. 2017. Temperate demersal gillnet and demersal longline fisheries status report. In Fletcher, W.J., Mumme, M.D., and Webster, F.J., editors. Status reports of the fisheries and aquatic resources of Western Australia 2015/16: The State of Fisheries. Department of Fisheries of Western Australia, Perth, pp 202-206. 
409 Chapman, B.B., Hulthen, K., Brodersen, J., Nilsson, P.A., Skov, C., Hansson, L.A., and 410 Bronmark, C. 2012. Partial migration in fishes: causes and consequences. Journal of $411 \quad$ Fish Biology 81:456-478.

412 Chapman, D.D., Feldheim, K.A.. Papastamatiou. Y.P., and Hueter. R.E. 2015. There and 413 back again: a review of residency and return migrations in sharks, with implications for 414 population structure and management. Annual Review of Marine Science 7:547-570.

415 Daly, R., Smale, M.J., Cowley, P.D., and Froneman, P.W. 2014. Residency patterns and 416 migration dynamics of adult bull sharks (Carcharhinus leucas) on the east coast of $417 \quad$ Southern Africa. PLoS ONE 9:e109357.

Dicken, M.L., Booth, A.J., Smale, M.J., and Cliff, G. 2007. Spatial and seasonal distribution patterns of juvenile and adult raggedtooth sharks (Carcharias taurus) tagged off the east coast of South Africa. Marine and Freshwater Research 58:127-134.

Espinoza, M., Heupel, M.R., Tobin, A.J., and Simpfendorfer, C.A. 2016. Evidence of partial migration in a large coastal predator: opportunistic foraging and reproduction as key drivers? PloS One 11: e0147608.

Fletcher, W.J., and Santoro, K. 2012. Status report of the fisheries and aquatic resources of Western Australia 2011/2012: The State of the Fisheries. Department of Fisheries of Western Australia, Perth.

Gelman, A. and Rubin, D.B. 1992. Inference from iterative simulation using multiple sequences. Statistical Science, pp.457-472.

Geraghty P.T., Williamson, J.E., Macbeth, W.G., Blower, D.C., Morgan, J.A.T., Johnson, G., Ovenden, J.R., and Gillings, M.R. 2014. Genetic structure and diversity of two highly vulnerable carcharhinids in Australian waters. Endangered Species Research 24:45-60. 
432 Grubbs, R.D., Musick, J.A., Conrath, C.L., and Romine, J. 2005. Long-term movements, migration, and temporal delineation of summer nurseries for juvenile sandbar sharks in the Chesapeake Bay region. In McCandless, C.T., Kohler, N.E., and Pratt, H.L.J., editors. Shark nursery grounds of the Gulf of Mexico and the East Coast waters of the United States. American Fisheries Society Symposium 50: 87-108.

Guan, W., Cao, J., Chen, Y., and Cieri, M. 2013. Impacts of population and fishery spatial structures on fishery stock assessment. Canadian Journal of Fisheries and Aquatic Sciences 1189: 1178-1189.

Heupel, M.R., Simpfendorfer, C.A., Espinoza, M., Smoothey, A.F., Tobin, A., and Peddemors, V. 2015. Conservation challenges of sharks with continental scale migrations. Frontiers in Marine Science 2:1-7.

Heupel M., and McAuley, R.B. 2007. Sharks and rays (Chondrichthyans) in the North-west Marine Region, report to the Department of the Environment, Water, Heritage and the Arts, WA Fisheries and Marine Research Laboratory, Department of Fisheries, Western Australia, Perth.

Heupel, M.R., Simpfendorfer, C.A., and Hueter, R.E. 2004. Estimation of shark home ranges using passive monitoring techniques. Environmental Biology of Fishes 71:135-142.

Hilborn, R. 1990. Determination of Fish Movement Patterns from Tag Recoveries using Maximum Likelihood Estimators. Canadian Journal of Fisheries and Aquatic Science 47:635-643.

Hoffmayer, E.R., Franks, J.S., Driggers, W.B., McKinney, J.A., Hendon, J.M., and Quattro, J.M. 2014. Habitat, movements and environmental preferences of dusky sharks, Carcharhinus obscurus, in the northern Gulf of Mexico. Marine Biology 161:911-924. 
455 Hueter, R.E., Heupel, M.R., Heist, E.J., and Keeney, D.B. 2005. Evidence of philopatry in 456 sharks and implications for the management of shark fisheries. Journal of Northwest $457 \quad$ Atlantic Fishery Science 37:239-247.

458

Hussey, N.E., McCarthy, I.D., Dudley, S.F.J., and Mann, B.Q. 2009. Nursery grounds, movement patterns and growth rates of dusky sharks, Carcharhinus obscurus: a longterm tag and release study in South African waters. Marine and Freshwater Research 60:571-583.

Jorgensen, S. J., Reeb, C.A., Chapple, T.K., Anderson, S., Perle, C., Van Sommeran, S.R., Fritz-Cope, C., Brown, A.C., Klimley, A.P., and Block, B.A. 2010. Philopatry and migration of Pacific white sharks. Proceedings of the Royal Society B: Biological Sciences 277:679-688.

Kneebone, J., Chisholm, J., and Skomal, G.B. 2012. Seasonal residency, habitat use, and site fidelity of juvenile sand tiger sharks Carcharias taurus in a Massachusetts estuary. Marine Ecology Progress Series 471:165-181.

Last P.R., and Stevens, J.D. 2009. Sharks and rays of Australia (second edition). CSIRO Publishing, Collingwood, Victoria.

Lea, J. S.E., Wetherbee, B.M., Queiroz, N., Burnie, N., Aming, C., Sousa, L.L., Mucientes, G.R., Humphries, N.E., Harvey, G.M., Sims, D.W., and Shivji, M.S. 2015. Repeated, long-distance migrations by a philopatric predator targeting highly contrasting ecosystems. Scientific Reports 5:11202.

Lorenzen, K., Steneck, R., Warner, R., Parma, A., Coleman, F., and Leber, K. 2010. The spatial dimensions of fisheries: putting it all in place. Bulletin of Marine Science 86:169-177. 
478 McAuley, R. 2010. Demersal gillnet and longline fisheries status report. In Fletcher, W.J., 479 and Santoro, K., editors. Status reports of the fisheries and aquatic resources of Western Australia 2009/10. Department of Fisheries of Western Australia, Perth, pp 246-259.

481

482

483

484

McAuley, R., and Simpfendorfer, C. 2003. Catch composition of the Western Australian temperate demersal gillnet and demersal longline fisheries, 1994 to 1999. Fisheries Research Report No. 146, Department of Fisheries, Western Australia, 78 pp.

McAuley, R., Lenanton, R., Chidlow, J., Allison, R., and Heist, E. 2005. Biology and stock assessment of the thickskin (sandbar) shark, Carcharhinus plumbeus, in Western Australia and further refinement of the dusky shark, Carcharhinus obscurus, stock assessment. Western Australia. Fisheries Research Report No. 151. Department of Fisheries, Western Australia. 132 pp.

McAuley, R., Simpfendorfer, C., and Hall, N. 2007. A method for evaluating the impacts of fishing mortality and stochastic influences on the demography of two long-lived shark stocks. ICES Journal of Marine Science 64:1710-1722.

McAuley, R, Bruce, B., Keay, I., Mountford, S., and Pinnell, T. 2016. Evaluation of passive acoustic telemetry approaches for monitoring and mitigating shark hazards off the coast of Western Australia. Fisheries Research Report No. 273, Department of Fisheries, Western Australia. 88pp.

Papastamatiou, Y.P., Meyer, C.G., Carvalho, F., Dale, J., Hutchinson, M., and Holland, K. 2013. Telemetry and random walk models reveal complex patterns of partial migration in a large marine predator. Ecology 94:2595-2606.

Plummer, M. 2003. JAGS: A program for analysis of Bayesian graphical models using Gibbs sampling. Proceedings of the 3rd International Workshop on Distributed Statistical 

Computing.

502

503

504

505

506

507

508

R Development CoreTeam. 2014. R: A language and environment for statistical computing. R Foundation for Statistical Computing, Vienna, Austria.

Rogers, P., Huveneers, C., Goldsworthy, S.D., Mitchell, J.G., and Seuront, L. 2013. Broadscale movements and pelagic habitat of the dusky shark Carcharhinus obscurus off southern Australia determined using pop-up satellite archival tags. Fisheries Oceanography 22:102-112.

Romine, J., Musick, J., and Burgess, G. 2009. Demographic analyses of the dusky shark, Carcharhinus obscurus, in the Northwest Atlantic incorporating hooking mortality estimates and revised reproductive parameters. Environmental Biology of Fishes 84:277-289.

Ryan, K., Hall, N., Lai, E.K., Smallwood, C.B., Taylor, S.M., and Wise, B.S. 2015. Statewide survey of boat-based recreational fishing in Western Australia 2013/14. Fisheries Research Report No. 268, Department of Fisheries, Western Australia. 208pp.

Schlaff, A.M., Heupel, M.R., and Simpfendorfer, C.A. 2014. Influence of environmental factors on shark and ray movement, behaviour and habitat use: a review. Reviews in Fish Biology and Fisheries 24:1089-1103.

Shaw, A.K., and Couzin, I.D. 2013. Migration or residency? the evolution of movement behavior and information usage in seasonal environments. The American Naturalist 181:114-124.

Simpfendorfer, C.A., McAuley, R., Chidlow, J.A., Lenanton, R., Hall, N., and Bastow, T. 1999. Biology and stock assessment of Western Australia's commercially important 
shark species. Final Report to the Fisheries Research and Development Corporation for Project Number 96/130. Department of Fisheries, Perth, Western Australia. 105 pp.

Simpfendorfer, C.A., McAuley, R.B., Chidlow, J.A., and Unsworth, P. 2002. Validated age and growth of the dusky shark, Carcharhinus obscurus, from Western Australian waters. Marine and Freshwater Research 53:567-573.

Skomal, G.B., Zeeman, S.I., Chisholm, J.H., Summers, E.L., Walsh, H.J., McMahon, K.W., and Thorrold, S.R. 2009. Transequatorial migrations by basking sharks in the Western Atlantic Ocean. Current Biology 19:1019-1022.

Speed, C.W., Field, I.C., Meekan, M.G., and Bradshaw, C.J.A. 2010. Complexities of coastal shark movements and their implications for management. Marine Ecology Progress Series 408:275-293.

Walker, T.I., Taylor, B.L., Brown, L.P.and Punt, A.E. 2008. Embracing movement and stock structure for assessment of Galeorhinus galeus harvested off southern Australia. In Camhi, M., and Pikitch, E., editors. Sharks of the Open Ocean: Biology, Fisheries and Conservation. Blackwell Publishing, Oxford, UK, pp 369-396.

Webster, M.S., Marra, P.P., Haig, S.M., Bensch, S., and Holmes. R.T. 2002. Links between worlds: unraveling migratory connectivity. Trends in Ecology and Evolution 17:76-83. 
542 Table 1. Minimum, maximum and mean number of daily detections per shark for each array

\begin{tabular}{lccc}
\hline Array & Minimum & Mean $( \pm \mathrm{SD})$ & Maximum \\
\hline Ningaloo & 1 & $7.30( \pm 11.76)$ & 96 \\
Perth & 1 & $2.05( \pm 4.07)$ & 32 \\
Southern & 1 & $4.21( \pm 3.80)$ & 24 \\
\hline
\end{tabular}

543

544 Table 2. Summary of parameter estimates for each sex (median and credibility intervals, CI)

\begin{tabular}{|c|c|c|c|c|c|}
\hline \multirow[b]{3}{*}{ Parameter } & \multirow[b]{3}{*}{ Month $(m)$} & \multicolumn{4}{|c|}{$\operatorname{Sex}(s)$} \\
\hline & & \multicolumn{2}{|c|}{ Female } & \multicolumn{2}{|r|}{ Male } \\
\hline & & Median & $95 \% \mathrm{CI}$ & Median & $95 \% \mathrm{CI}$ \\
\hline \multirow{12}{*}{$\alpha$} & January & 0.49 & $0.26-0.72$ & 0.12 & $0.00-0.54$ \\
\hline & February & 0.55 & $0.29-0.81$ & 0.18 & $0.01-0.71$ \\
\hline & March & 0.59 & $0.33-0.82$ & 0.23 & $0.01-0.82$ \\
\hline & April & 0.57 & $0.33-0.79$ & 0.32 & $0.05-0.80$ \\
\hline & May & 0.95 & $0.83-1.0$ & 0.66 & $0.41-0.93$ \\
\hline & June & 0.92 & $0.77-0.99$ & 0.47 & $0.19-0.81$ \\
\hline & July & 0.97 & $0.85-1.0$ & 0.92 & $0.65-1.0$ \\
\hline & August & 0.96 & $0.83-1.0$ & 0.94 & $0.72-1.0$ \\
\hline & September & 0.94 & $0.75-1.0$ & 0.75 & $0.38-0.98$ \\
\hline & October & 0.95 & $0.76-1.0$ & 0.79 & $0.43-0.99$ \\
\hline & November & 0.90 & $0.7-0.99$ & 0.53 & $0.23-0.86$ \\
\hline & December & 0.49 & $0.22-0.80$ & 0.50 & $0.2-0.85$ \\
\hline$\beta$ & & 221.97 & $214.96-227.24$ & 212.09 & $190.68-227.87$ \\
\hline$\varphi$ & & -8.93 & $-13.38--6.0$ & -18.84 & $-36.33--11.15$ \\
\hline
\end{tabular}




\section{$547 \quad$ Figure legends}

548 Fig. 1. Study site. Plot showing the location of receivers (shown as white dots in the left and 549 bottom panels and black dots in the right panel), the number of sharks detected per receiver 550 (shown as a color gradient) and the number of sharks detected per array. The turning points 551 used to calculate the distance travelled are shown as white dots in the right panel (from north 552 to south: North West Cape, Shark Bay and Cape Leeuwin) and the area closed to commercial 553 shark fishing is shaded in the top of the right panel.

554 Fig. 2. Distance travelled (a) and number of days (b) for the north-south and south-north 555 displacements of migratory sharks. Each bar represents a migratory individual. In the mid 556 panel, the fork length (in $\mathrm{cm}$ ) and sex of each individual are shown above and below the bar, 557 respectively. Also shown is frequency distribution of rate of movements for the north-south 558 and south-north displacements (c).

559 Fig. 3. Daily presence/absence of tagged females showing residency in northern (Ningaloo 560 array) and southern (Perth and Southern arrays) Western Australia. Tagged individuals are 561 sorted by fork length (FL). The winter/spring seasons are shaded in dark grey and the 562 summer/autumn seasons are shaded in light grey. The open circle shows the release location 563 and date.

564 Fig. 4. Daily presence/absence of tagged males showing residency in northern (Ningaloo 565 array) and southern (Perth and Southern arrays) Western Australia. Tagged individuals are 566 sorted by fork length (FL). The winter/spring seasons are shaded in dark grey and the 567 summer/autumn seasons are shaded in light grey. The open circle shows the release location 568 and date.

569 Fig. 5. Number of detected migratory sharks by location and week of the year. 
570 Fig. 6. Dusky shark migration. The upper panel shows the probability of migrating north in

571 January and August for different sizes of female and male dusky sharks with associated 95\%

572 CI (credible intervals). The lower panel shows the monthly probability of migrating north for

573 female and male dusky sharks with associated 95\% CI. 
Fig. 1
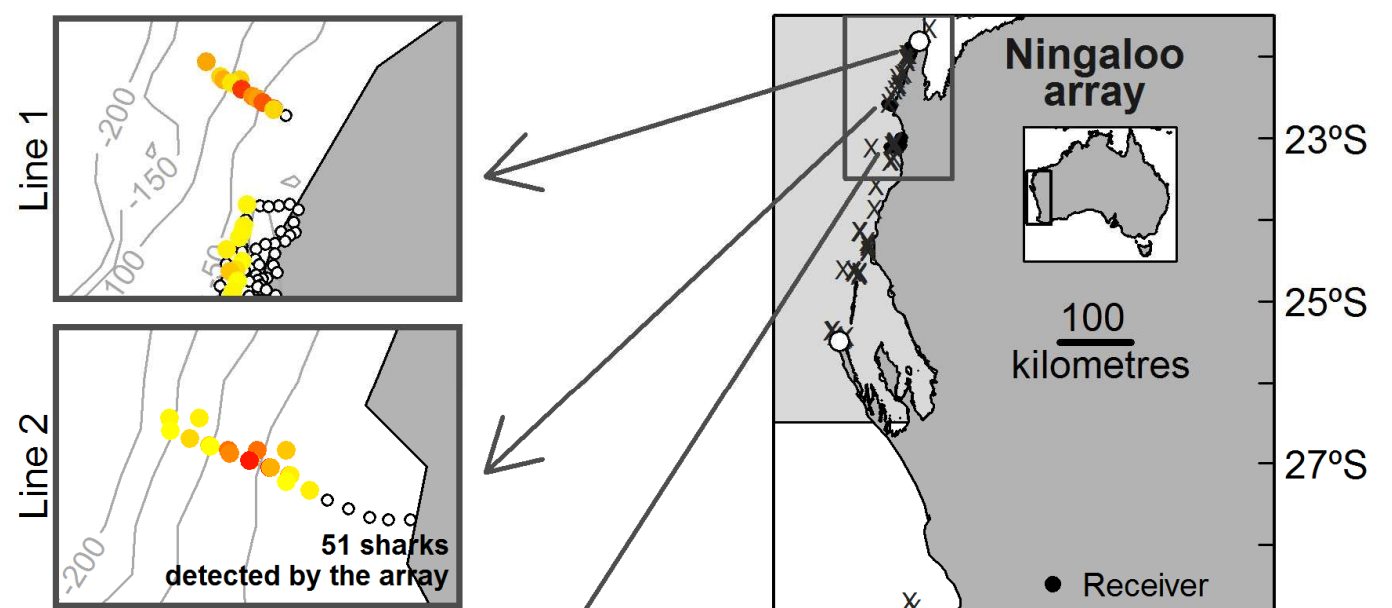

$25^{\circ} \mathrm{S}$
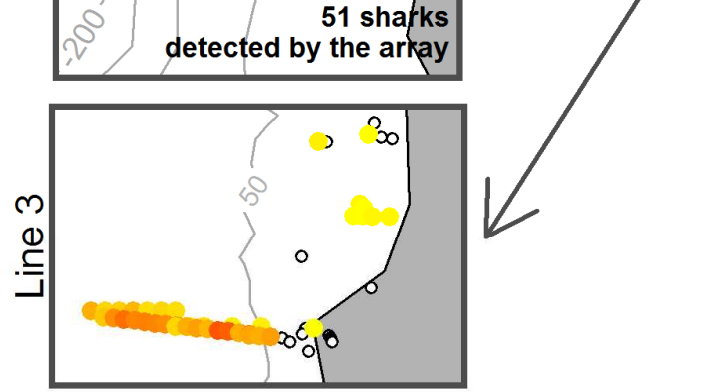
577 Fig. 2
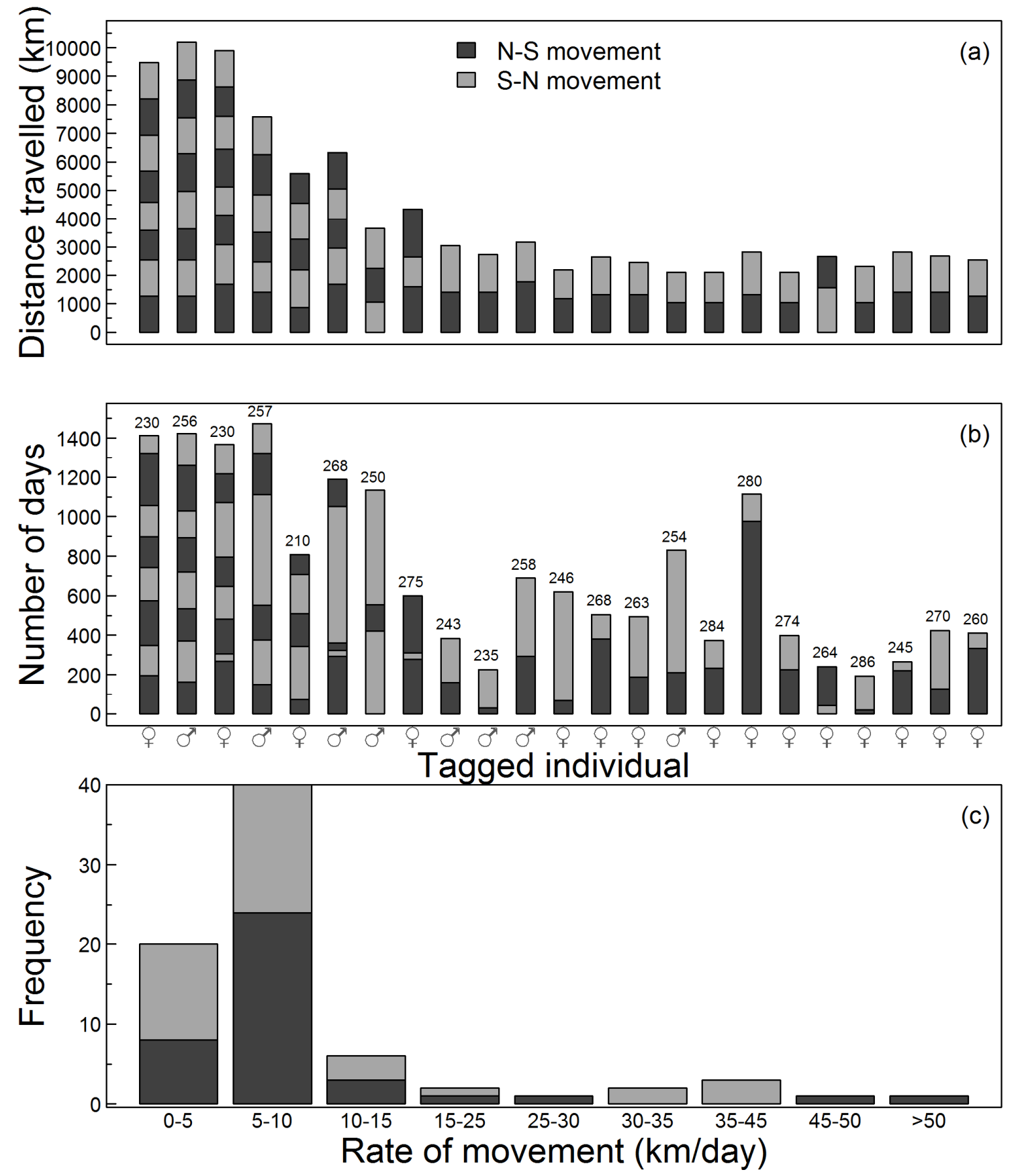
Fig. 3

(FL @ 50\% maturity= $254 \mathrm{~cm})$ - North - South

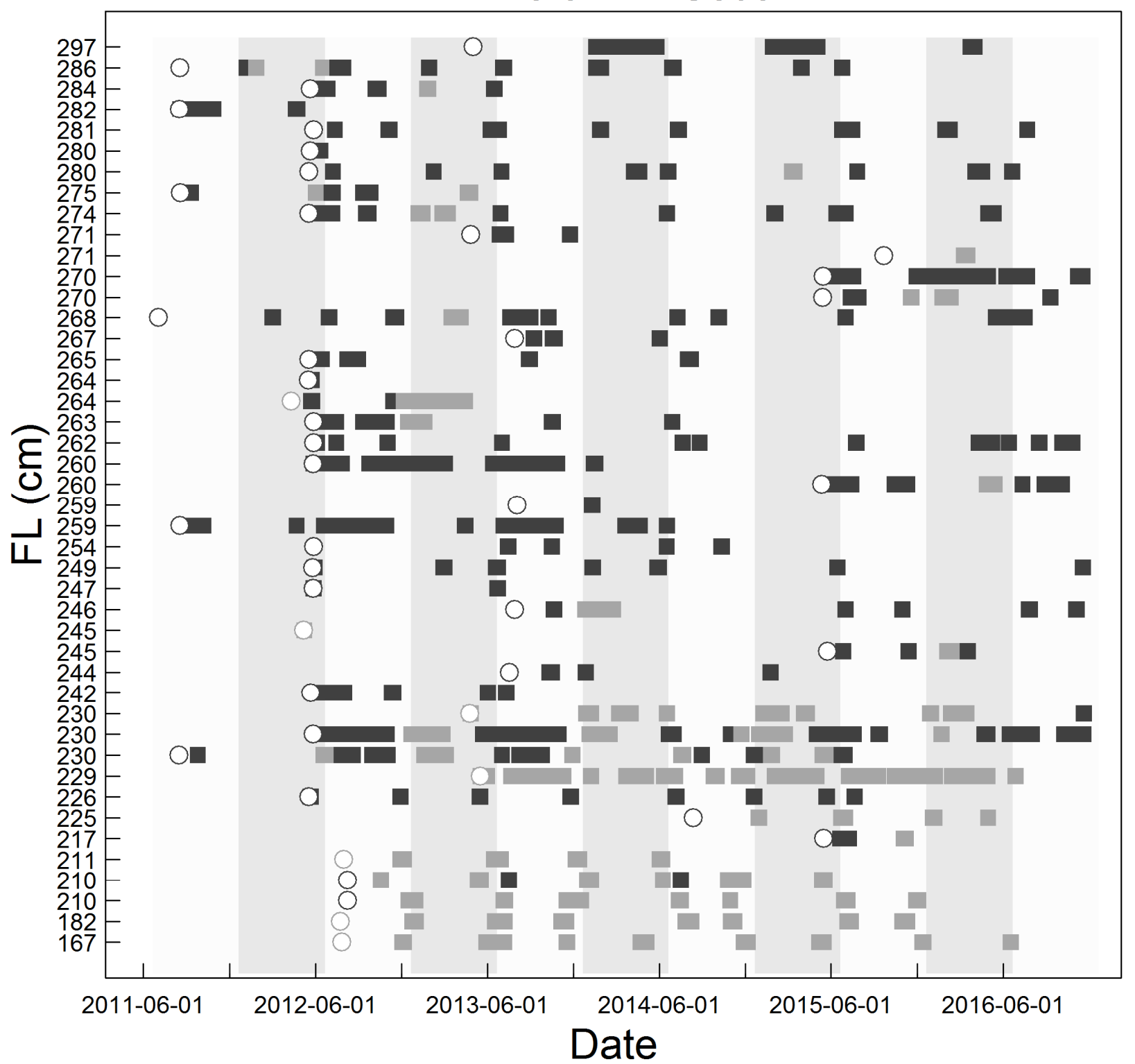


583 Fig. 4

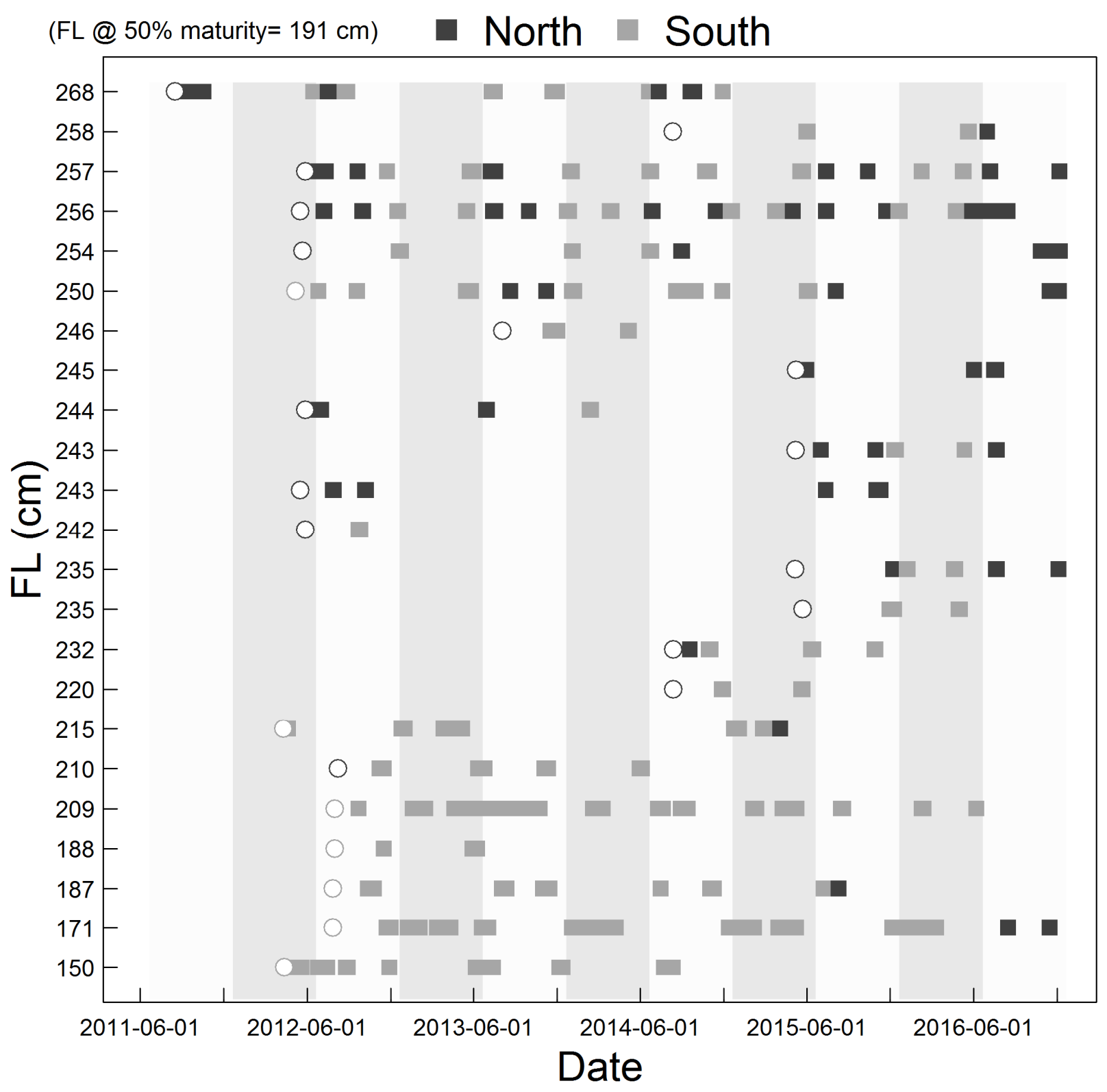


Fig. 5

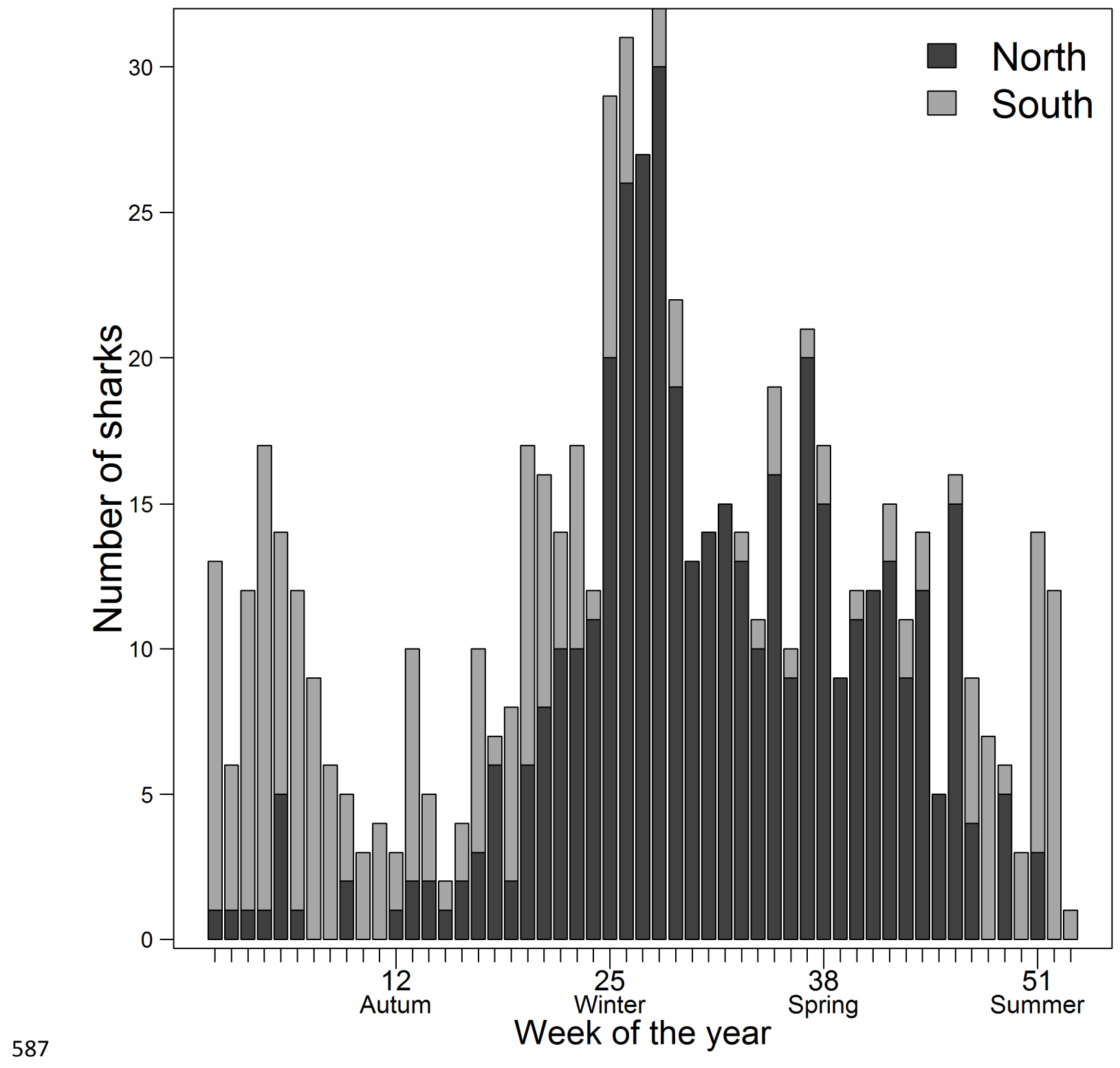


589 Fig. 6

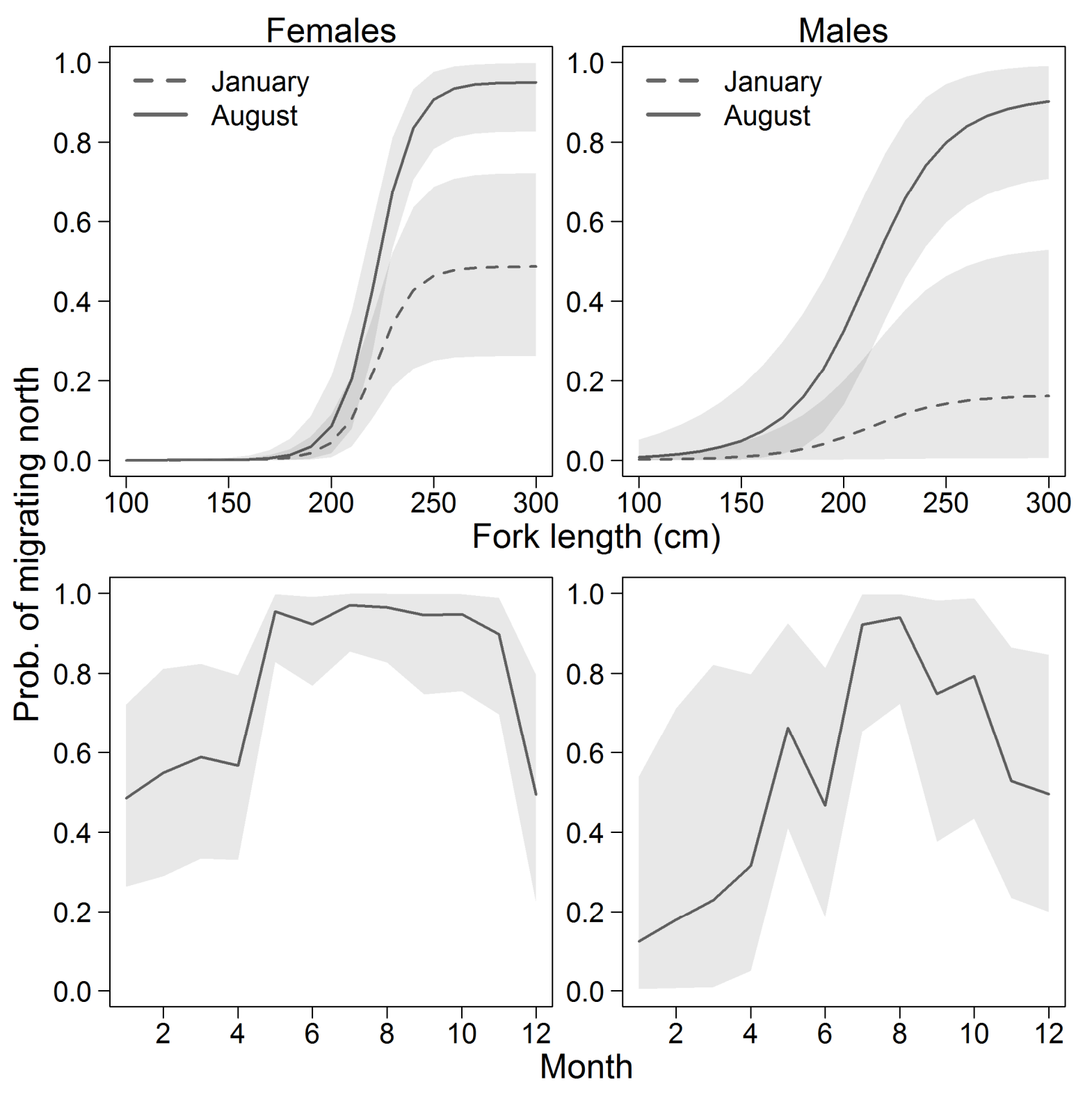

